\title{
The effect of constant power shock on the acquisition of a discriminated avoidance response
}

HARRY M. B. HURWITZ AND PAUL V. DILLOW

UNIVERSITY OF TENNESSEE

Forty-five female rats were trained under a discriminated avoidance learning procedure in a lever-pressing apparatus, constant power serving as the aversive stimulus. An analysis of variance failed to reveal differences due to shock intensity but indicated an excessively large inter-S variance.

In most recent studies of discriminated avoidance learning the aversive stimulus is provided by a constant current source although Campbell \& Teghtsoonian (1958) have shown earlier the advantages of using constant power. The present experiment was designed to investigate the effect of different intensities of shock provided by a constant power source on the rate of learning a discriminated-avoidance response in a lever-pressing apparatus under a procedure which had previously been shown to result in rapid and effective training (Hurwitz, 1964).

Subjects

The Ss were 45 three-month-old female hooded rats purchased from the closed colony maintained by the animal laboratories of the Medical Research Council, U.K. They were randomly assigned to five experimental groups.

\section{Apparatus}

The lever-pressing apparatus was an all-metal chamber (12 in. $x 6$ in. $x 9$ in.) whose floors consisted of five $1 / 4$ in. bars. The lever protruded through one of the walls $(2-1 / 2$ in. above floor level) and required a 5 gm downward pressure. Shock was applied via a con- stant-power scrambled source (Behavior Apparatus, unit $A$ 035) with a range of $0-250 \mathrm{~mW}$ under a varying load range of $30 \mathrm{~K}-150 \mathrm{~K}$. The chamber was housed in a sound-insulated cabinet. Two panel indicator lamps mounted on the ceiling served as signal-lights.

\section{Procedure}

Each S was given one training session lasting for $4 \mathrm{hr}$. Shortly after a $\mathrm{S}$ was placed in the chamber, the signal (light) was presented and unless a lever press occurred within 9 sec., the first of a series of brief shocks $(0.5$ sec. on; 5 sec. off) was given. The signal terminated and the train of shocks was suspended only when the lever was momentarily activated. A press during the short shock-on period had no effect. After an intertrial interval of 18 sec., the signal and shock series was resumed. Group 25 received $25 \mathrm{~mW}$ shock; Group $50,50 \mathrm{~mW}$; Group 100, $100 \mathrm{~mW}$; Group 150, $150 \mathrm{~mW}$; Group 200. $200 \mathrm{~mW}$. The number of shocks per hour was used as the principal measure of performance.

Results

An analysis of variance of groups by hours by subjects was performed. The group effects were not significant, $F=.7, d f=4 / 40, p>.25$. The group by hour interaction was also not significant, $F=1.0, \mathrm{df}=12 / 120, \mathrm{p}>.25$. The hours effect was significant, $F=21, d f=3 / 120, p<.01$. A check on the homogeneity of the partitioning of the sums of squares indicated that the variance between the five groups was homogeneous. A test of the simple main effect of intensity against hours failed to show any significant difference between groups for any hour.
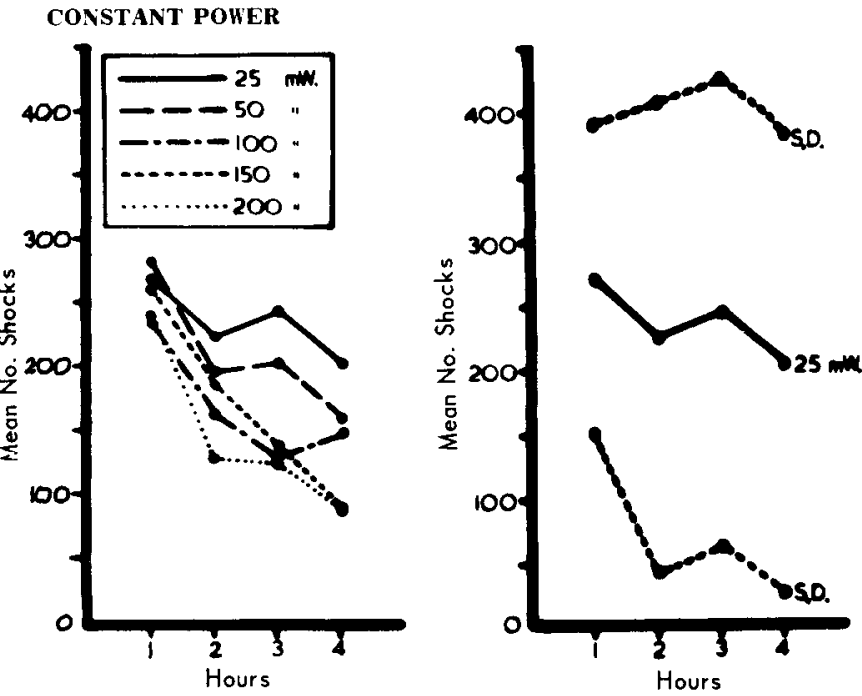

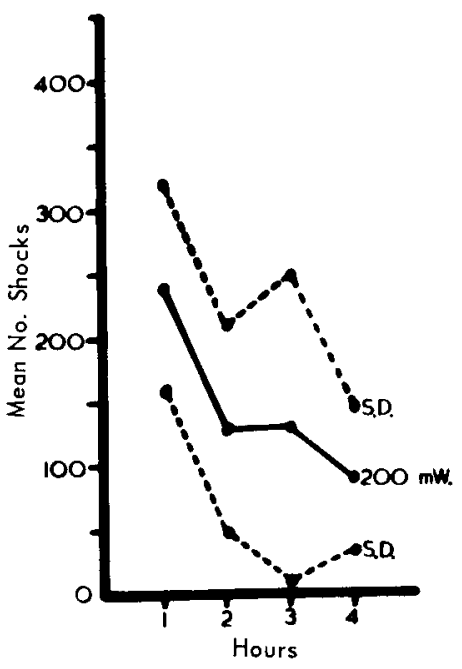

Fig. 1. The figures shown from left to right are: (I) Mean number of shocks obtained by several groups as a function of session length. (II) Mean number of shocks obtained and standard deviation of scores for Ss receiving $25 \mathrm{~mW}$. (III) Mean number of shocks obtained and standard deviation of scores for Ss receiving $200 \mathrm{~mW}$. 


\section{Discussion}

The results, which are lllustrated in Fig. 1, lead to the conclusion that different shock intensities as supplied by a constant-power source, do not determine in a systematic manner the rate of learning a discriminated avoidance response. Notable is the large variance obtained under the lowest shock intensity. Experiments using a similar (Hurwitz, 1966) or related procedure (Bolles \& Warren, 1965; Moyer \& Korn, 1964) but employing constant current have produced more positive results, namely that intensities above $1.0 \mathrm{ma}$ actively impede learning whereas intensities lower than $.2 \mathrm{ma}$ have minimal effects on the Ss.

\section{References}

Bolles, R. C., \& Warren, J. A. The acquisition of bar-press avoidance as a function of shock intensity. Psychon. Sci., 1965, 3 297-298.
Campbell, B. A., \& Teghtsoonian, R. Electrical and behavioral effects of different types of shock stimuli on rats. J. comp. physiol. Psychol., 1958, 51, 185-192

Hurwitz, H. M. B. Method for discriminated avoidance training. Science, 1964, 145, 1070-1071.

Hurwitz, Н. M. B. Discriminated avoidance training in rats. Science, $1964,146,1600$.

Hurwitz, H. M. B., \& Dillow, P. V. The effect of constant current shock intensities on the acquisition of a discriminated avoidance response. Psychon. Sci., 1966, 5, 109-110.

Moyer, K. A., \& Kom, J. H. Effect of UCS intensity on the acquisition and extinction of an avoidance response. J.exp. Psychol. $1964,67,353-359$.

\section{Note}

1. This investigation was supported by a grant from Birkbeck College, London, on "Factors of conditioned behavior". Both authors are now at the University of Tennessee. 